\title{
CRIPPLE CARE IN SOUTH AFRICA
}

\author{
By LYDIA ERLANK, B.A. (Social Science). \\ Secretary for the National Council for the Care of Cripples in South Africa.
}

When we think of the handicapped in our community, it is essential that we should remember that cripples do not constitute a group on their own, but form a normal and integral part of the life and activities of any society. As such they have a right to our interest and assistance.

The problems of the handicapped are basically the problems of all people, except that in the case of the handicapped, the problems take on a more accentuated form.

To help the crippled to the best of our ability, it is essential that we should believe that by means of prevention, early specialist treatment, thorough aftercare, proper training and selective placement, he will be able to fill his position in the community as competently as the next person.

The development of orthopaedic services in South Africa clearly illustrates that most forms of social responsibility are accepted by the public and Government only after having first been realised and developed by some individual or small group of persons.

The first person to take an active interest in our cripple problem, and to act in a material and positive way, was Lord Nuffield, who in I937 made his magnificent gift of $E_{I 00,000}$ to South Africa for the development of orthopaedic services. This led to the formation in 1939 of the National Council for the Care of Cripples with the object of establishing a complete orthopaedic service for the country and to correlate and co-ordinate the work done in this field.

During the past nine years, which was a difficult period on account of war conditions, the Council has been successful in establishing a framework for a complete orthopaedic service. Before I9.39 work for cripples was limited to certain areas. It was tackled on a national basis only after that year.

The National Council, with the aid of generous Nuffield grants, stimulated the erection of orthopaedic homes and wards in hospitals where cripples can receive the prescribed treatment for months, and even years, if necessary. Although still inadequate, the basis has been laid. It now requires extension.

Accommodation for cases suffering from bone tuberculosis, the main cause of crippling, is sadly inadequate, mainly due to the indecision of the Central Government and Provinces in regard to the question of responsibility for cases suffering from surgical tuberculosis.

The Council realised that the provision of orthopaedic beds without snecialised orthopaedic treatment was no solution. Orthopaedic work has to be performed by persons specially trained in this branch of surgery

A grant was allocated to each of the Universities of Cape Town and the Witwatersrand for the establishment of Lectureships in orthopaedics, and a further grant was made for the establishment of a training school for European nurses at Cape Town Bursaries were granted for post-graduate training in orthopaedic surgery, and so far seven doctors have qualified as orthopaedic surgeons under this scheme, while 3 I nurses, with the assistance of National Council bursaries, have completed their studies in orthopaedic nursing. Arrangements are being made for the establishment in the Transvaal of a similar course for Native nurses.

The National Council has also made it possible for five orthopaedic technicians to undergo a five-year training course at the Government Limb Factory. These persons are doing a great work by making the appliances and limbs to put the cripples "on their feet." Through the efforts of the National Council, the Society of Orthopaedic and Surgical Technicians of South Africa was formed with the object of advancing the interests of orthopaedic technicians in the country.

Grants have also been made for other purposes. The Council, realising the inestimable value of the physiotherapist in this great service, recently made available a grant of $t_{300}$ for the training of such a person.

Vocational Training Centres for. Europeans and Coloureds at Stellenbosch and Cape Town respectively are being planned, and it is hoped that building will be started in the not too distant future. These institutions will provide the necessary facilities for European and Coloured cripples to become fully trained for whatever employment their residual abilities and interest will allow.

A national survey of cripples is being conducted to ensure that every cripple receives the treatment and assistance to which he is entitled. Social workers attached to the various cripple care associations are doing a great work in helping cripples to find their niche in the community.

Orthopaedic clinics are being established throughout the country and the ideals of the National Council, viz, that cripples should receive treatment in the very early stages and that satisfactory aftercare should be exercised, are materialising. The scheme, though still in its infancy, has already shown magnificent results.

The treatment of the crippled and equipping them for life is not only a social service; it has an economic aspect. The cripple whose life is changed from one of dependence to one of usefulness becomes an asset to the State instead of a liability, and as such it is only logical that the rehabilitation of the cripple should receive liberal Government support.

We hope that it will not be long before South Africa will realise the truth of the following extract from the "Crippled Child's Bill of Rights" adopted at the Second World Conference on the problem of the cripple:

"In brief, not only for its own sake, but for the benefit of society as a whole, every child crippled has the right to the best body which modern science can help it to secure, the best mind which modern education can provide, the best training which modern vocational guidance can give, the best position in life which his physical condition, perfected as best it may be, will permit, and the best opportunity for spiritual development which its environment affords." 